\title{
Determination of the Spiral Conformation of Aquaspirillum spp. by Scanning Electron Microscopy of Elongated Cells Induced by Cephalexin Treatment
}

\author{
By HISANORI KONISHI* AND ZENSAKU YOSHII \\ Department of Microbiology, Yamaguchi University School of Medicine, 1144 Kogushi, Ube-shi, \\ Yamaguchi-ken 755, Japan
}

(Received 19 August 1985; revised 17 October 1985)

\begin{abstract}
The effect of the $\beta$-lactam antibiotic cephalexin on the spiral conformation of cells of Aquaspirillum spp. was examined by scanning electron microscopy. $A$. itersonii and $A$. peregrinum, which are known to have a left-handed spiral shape, elongated and still showed lefthanded spirals in medium containing cephalexin. The spiral conformation of the elongated cells is therefore considered to represent the natural condition. The spiral conformations of $A$. metamorphum and $A$. psychrophilum grown in ordinary cultures were difficult to determine because they have short cells without a complete spiral. After cephalexin treatment, the cells of these species elongated and displayed spiral forms, right-handed in A. metamorphum and lefthanded in $A$. psychrophilum. This elongation method may be useful for checking and determination of the spiral handedness of short spiral or curved bacteria such as vibrios.
\end{abstract}

\section{INTRODUCTION}

Members of the genus Spirillum as described by Krieg \& Smibert (1974) have a spiral shape, a rigid cell body, polytrichous polar flagella and a unique corkscrew motion. This genus has since been divided into three genera, Spirillum, Aquaspirillum and Oceanospirillum (Krieg, 1984). The spiral conformation of these bacteria is considered to be important for their classification and in relation to their mechanism of motility.

Terasaki (1972) and Krieg (1976) described the spiral handedness of various spirilla as observed by light microscopy. Scanning electron microscopy has been recently used to describe the spiral conformation of 10 species of Spirillum (sensu lato) and one species of Rhodospirillum (Yoshii et al., 1982). Scanning electron microscopy provides more accurate results than light microscopy, since it produces three-dimensional images with higher resolving power. However, the spiral handedness of three species, Aquaspirillum (formerly Spirillum) metamorphum, $A$. (S.) psychrophilum and 'Spirillum lunatum', could not be determined because their short cells did not form complete spirals.

In the present study we attempted to determine the spiral conformation of these three species by scanning electron microscopy of elongated cells induced by treatment with the $\beta$-lactam antibiotic cephalexin.

\section{METHODS}

Strains. Aquaspirillum (formerly Spirillum) metamorphum ATCC 15280 and A. (S.) itersonii ATCC 12639 were obtained from Dr Terasaki, Suzugamine Women's College, Hiroshima, Japan. A. (S.) psychrophilum IFO 13611 , ' $S$. lunatum' IFO 3985 and $A$. (S.) peregrinum IFO 13617 were obtained from the Institute for Fermentation, Osaka, Japan. Escherichia coli $\mathrm{W}$ strain has been maintained in our laboratory. A. itersonii and $A$. peregrinum were used as positive controls known to have a left-handed spiral (Yoshii $e t$ al., 1982) and $E$. coli was used as a negative control. 
Culture methods. Nutrient broth or nutrient agar (Nissui, Tokyo, Japan) was used for growth of $E$. coli, and a modified nutrient broth or agar $\left(5 \mathrm{~g}\right.$ polypeptone and $3 \mathrm{~g}$ meat extract $\left.\mathrm{l}^{-1}, \mathrm{pH} 7.0\right)$ was used for the spirilla. Each organism was cultured on agar slopes at its optimal temperature. A. psychrophilum was incubated at $25^{\circ} \mathrm{C}$ for $3 \mathrm{~d}$, the other spirilla at $30^{\circ} \mathrm{C}$, and $E$. coli at $37^{\circ} \mathrm{C}$ for $2 \mathrm{~d}$. The cultures were transferred into liquid medium $\left(1.2 \times 10^{8}\right.$ to $5.0 \times 10^{8}$ organisms $\left.\mathrm{ml}^{-1}\right)$, incubated for $6 \mathrm{~h}$ at the optimal temperature and used as an inoculum.

Antibiotic. Cephalexin (Shionogi-Lilly Co.) was prepared by reconstitution with distilled water and filter sterilized by passage through $0.45 \mu \mathrm{m}$ filters.

Elongation treatment with cephalexin. Serial dilutions of cephalexin $\left(0.1\right.$ to $\left.250 \mu \mathrm{g} \mathrm{ml}^{-1}\right)$ were prepared in fresh broth and $2 \mathrm{ml}$ portions were placed in test tubes. Each tube was inoculated with $2 \mathrm{ml}$ of the appropriate culture and incubated for $24 \mathrm{~h}$ at its optimal temperature. Tubes containing $2 \mathrm{ml}$ fresh cephalexin-free medium inoculated and incubated in the same way were used as controls. Tubes which contained elongated cells when examined by dark-field light microscopy were selected and examined by scanning electron microscopy.

Scanning electron microscopy. Specimens were prepared as follows. The cultures were washed three times in saline solution by centrifugation at $1500 \mathrm{~g}$ for $10 \mathrm{~min}$ at $5{ }^{\circ} \mathrm{C}$ and treated by the double fixation method with $2 \%$ ( $v / v)$ glutaraldehyde/1\%(w/v) osmium tetroxide (Ryter \& Kellenberger, 1958). The fixed material was washed twice in distilled water and dehydrated with increasing concentrations of acetone prior to critical-point drying in carbon dioxide. The dried cells on glass slides or small sheets of filter paper were coated with gold/palladium alloy in an evaporator and observed by scanning electron microscopy (JEOL JSM-F7, $13 \mathrm{kV}$ ).

Spiral handedness. Spiral handedness was determined on printed photographs, carefully prepared so as not to make mirror images. The scanning electron microscope used made real images and not mirror images as described by Yoshii (1978). Right- (or left-) spiral handedness was defined as rotation clockwise (or counter-clockwise) while moving along the spiral away from the observer (Yoshii, 1978; Carleton et al., 1979).

\section{RESULTS AND DISCUSSION}

Five spirilla and one strain of $E$. coli were observed with or without cephalexin treatment by scanning electron microscopy.

In the absence of cephalexin, $A$. itersonii and $A$. peregrinum showed a left-handed spiral form (Fig. 1 a) as previously described (Yoshii et al., 1982). After cephalexin treatment, over $80 \%$ of the cells of both these species formed long filaments, but kept their native left-handed spiral forms at antibiotic concentrations of 0.5 to $2.5 \mu \mathrm{g} \mathrm{ml}^{-1}$ (A. itersonii) and 25 to $125 \mu \mathrm{g} \mathrm{ml}^{-1}$ (A. peregrinum) (Fig. $1 b$ ). No other marked changes in their morphology were observed at these concentrations. Although a change in handedness has been reported for a helical mutant of Bacillus subtilis when grown in different media (Mendelson, 1978), this was not observed as a result of the treatment in the present study. E. coli cells grown in ordinary culture were rod shaped, and although 20 to $30 \%$ of the population elongated when treated with between 25 and $125 \mu \mathrm{g}$ cephalexin $\mathrm{ml}^{-1}$, the elongated cells did not display any spiral forms (Fig. 2). These results demonstrate that these bacteria retain the original features of their spirality even in cephalexin-induced filaments. Thus the spiral handedness of the elongated cells is considered to represent the natural condition.

A. metamorphum, A. psychrophilum and ' $S$. lunatum' grown in cephalexin-free medium showed rod or short curved shapes with an incomplete spiral (Fig. $3 a, c$ ), and their spiral handedness could not be directly determined. After cephalexin treatment $\left(0.05\right.$ to $\left.0.5 \mu \mathrm{g} \mathrm{ml}^{-1}\right), 40$ to $50 \%$ of A. metamorphum cells become elongated; some organisms appeared damaged and others showed no change in their morphology. All the cells which elongated and showed complete spirals exhibited right-handed ones (Fig. $3 b$ ). Most A. psychrophilum cells exposed to 50 to $125 \mu \mathrm{g}$ cephalexin $\mathrm{ml}^{-1}$ elongated and also showed complete left-handed spiral forms (Fig. $3 d$ ). The handedness of ' $S$. lunatum' could not be determined, because it did not elongate and did not form a complete spiral at any concentration of cephalexin between 0.05 and $125 \mu \mathrm{g} \mathrm{ml}^{-1}$.

Terasaki (1972) described both $A$. psychrophilum and $A$. metamorphum as having a righthanded spiral. The right-handed conformation of $A$. metamorphum is confirmed in the present study. However, we found $A$. psychrophilum to have a left-handed spiral. The reasons for this difference in results are unknown. We consider that although spiral handedness is a stable characteristic, a change in handedness might occur during long-term maintenance, and that the results from scanning electron microscopy after cephalexin-induced elongation are probably more accurate. 

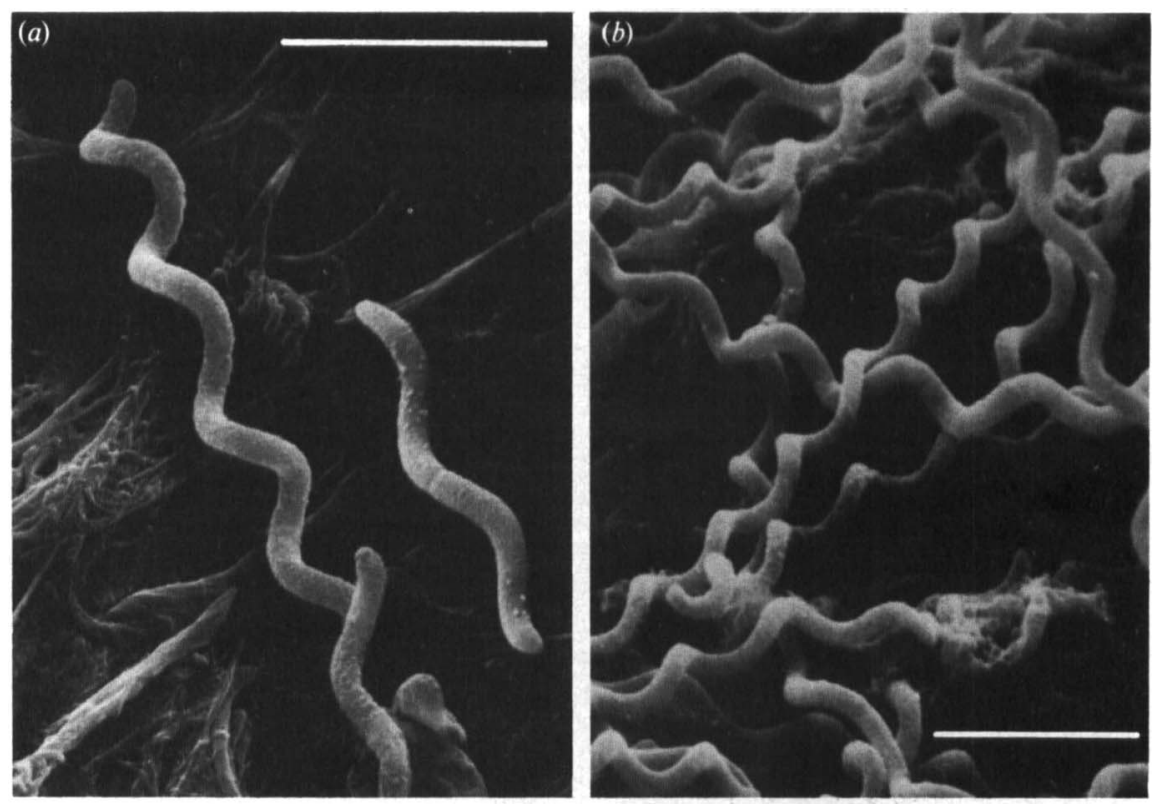

Fig. 1. Scanning electron micrographs of $A$. peregrinum. (a) Cells grown in cephalexin-free medium, showing a typical left-handed spiral shape. (b) Cells treated with $125 \mu \mathrm{g}$ cephalexin $\mathrm{ml}^{-1}$. Large numbers of elongated cells are observed, which display a left-handed spiral. No right-handed spiral forms were observed. Bars, $5 \mu \mathrm{m}$.

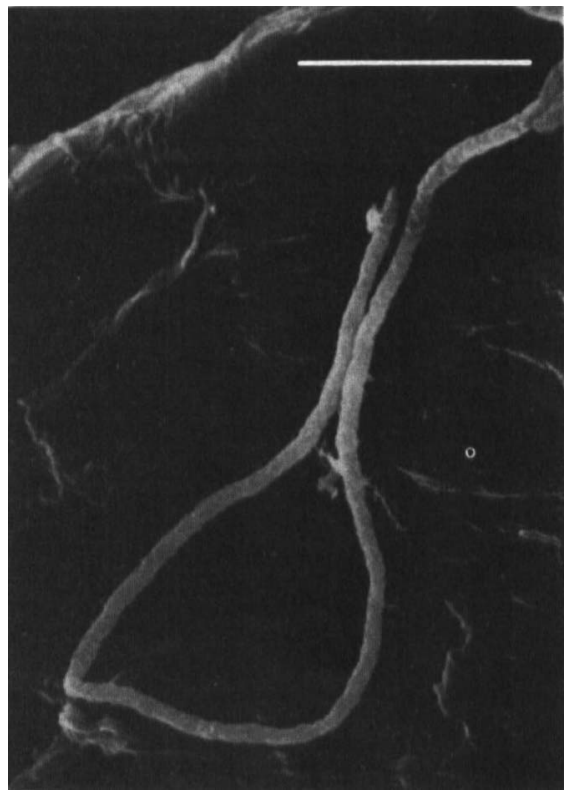

Fig. 2. Scanning electron micrograph of an elongated cell of $E$. coli treated with $125 \mu \mathrm{g}$ cephalexin $\mathrm{ml}^{-1}$. Bar, $10 \mu \mathrm{m}$. 

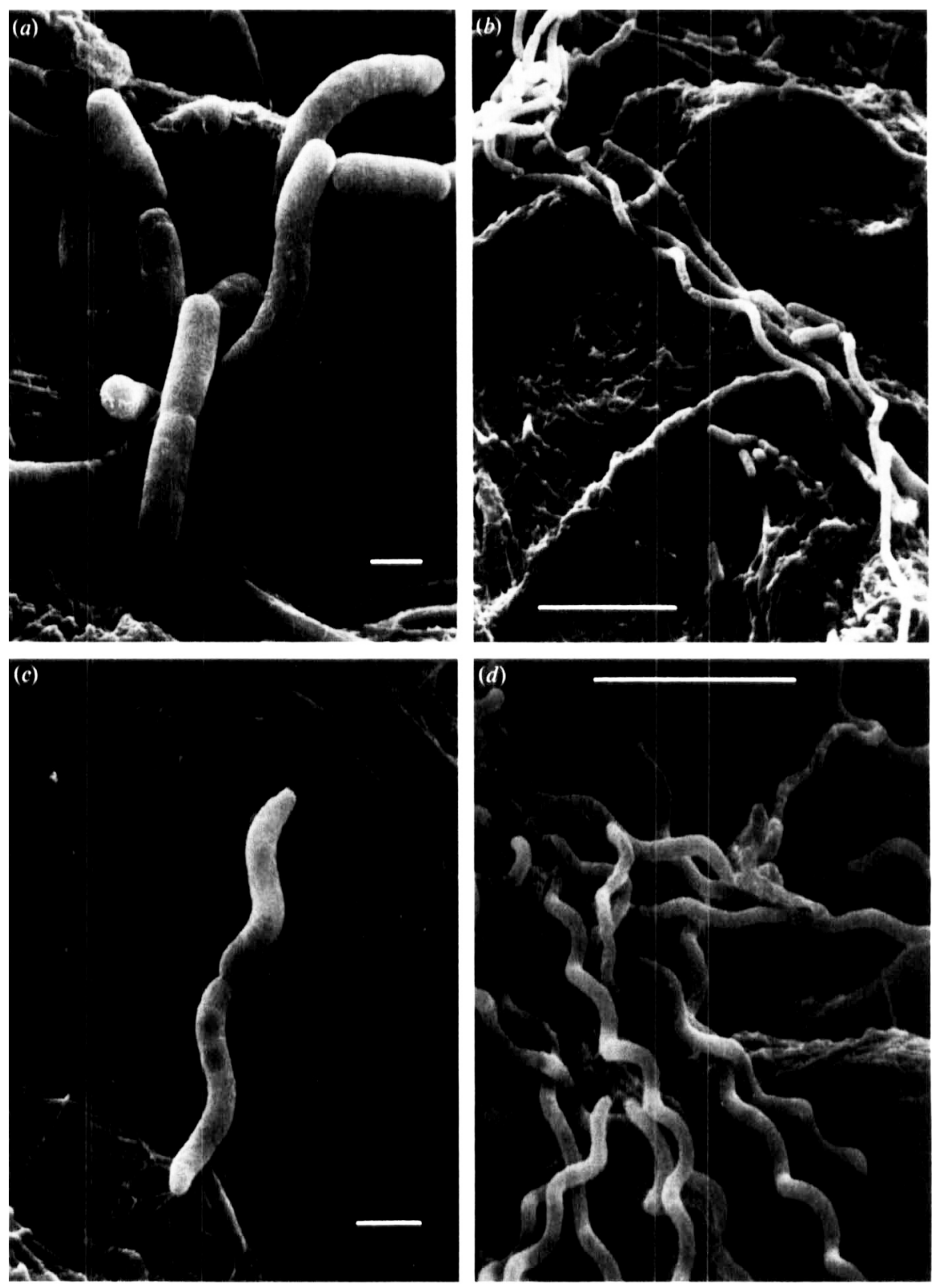

Fig. 3. (a) Scanning electron micrograph of $A$. metamorphum grown in cephalexin-free medium. Rodshaped or curved celis, whose spiral handedness was unclear, were observed. Bar, $1 \mu \mathrm{m}$. (b) Scanning electron micrograph of $A$. metamorphum treated with $0.05 \mu \mathrm{g}$ cephalexin $\mathrm{ml}^{-1}$. A few elongated cells with a right-handed spiral can be seen. Bar, $10 \mu \mathrm{m}$. (c) Scanning electron micrograph of $A$. psychrophilum grown in cephalexin-free medium. Short cells with incomplete spirals, whose spiral handedness was unclear, were observed. Bar, $1 \mu \mathrm{m}$. (d) Scanning electron micrograph of $A$. psychrophilum treated with $125 \mu \mathrm{g}$ cephalexin $\mathrm{ml}^{-1}$. Several extremely elongated cells with a left-handed spiral can be seen. Bar, $10 \mu \mathrm{m}$. 
The methods described may also be useful for checking and determination of the spiral handedness of other short spiral or curved bacteria such as vibrios.

\section{REFERENCES}

Carleton, O., Charon, N. W., Allender, P. \& O'Brien, S. (1979). Helix handedness of Leptospira interrogans as determined by scanning electron microscopy. Journal of Bacteriology 137, 1413-1416.

KRIEG, N. R. (1976). Biology of the chemoheterotrophic spirilla. Bacteriological Reviews 40, 55-115.

KRIEG, N. R. (1984). Aerobic/microaerophilic, motile, helical/vibrioid Gram-negative bacteria. In Bergey's Manual of Systematic Bacteriology, vol. 1, pp. 71124. Edited by N. R. Krieg. Baltimore: Williams \& Wilkins.

Krieg, N. R. \& Smibert, R. M. (1974). Spiral and curved bacteria. In Bergey's Manual of Determinative Bacteriology, 8th edn, pp. 196-216. Edited by R. E. Buchanan \& N. E. Gibbons. Baltimore: Williams \& Wilkins.

Mendelson, N. H. (1978). Helical Bacillus subtilis macrofibers: morphogenesis of a multicellular microorganism. Proceedings of the National Academy of Sciences of the United States of America 75, 24782482.

RYTER, A. \& Kellenberger, E. (1958). L'inclusion au polyester pour l'ultramicrotome. Journal of Ultrastructure Research 2, 200-214.

TerasakI, Y. (1972). Studies in the genus Spirillum Ehrenberg. I. Morphological, physiological, and biochemical characteristics of water spirilla. Bulletin of Suzugamine Women's College 16, 1-146.

YoshII, Z. (1978). Fundamental considerations and experimental conditions on the study of the spiraldirection of helical bacteria. Bulletin of Yamaguchi Medical School 25, 115-127.

Yoshi, Z., Konishi, H., Akitomi, H. \& Mizuno, A. (1982). Spirality of cell bodies in genus Spirillum and genus Rhodospirillum under scanning electron microscopy. Bulletin of Yamaguchi Medical School 29, 1-8. 